\title{
PNPLA3 as a Genetic Determinant of Risk for and Severity of Non-alcoholic Fatty Liver Disease Spectrum
}

\author{
Habeeb Salameh ${ }^{1}$, Muhannad Al Hanayneh ${ }^{1}$, Maen Masadeh ${ }^{2}$, Mohammed Naseemuddin $^{3}$, \\ Tasnia Matin ${ }^{3}$, Angelika Erwin ${ }^{4}$ and Ashwani K. Singal*5 \\ ${ }^{1}$ Division of Gastroenterology and Hepatology, Department of Internal Medicine, University of Texas Medical Branch, Galveston, \\ TX, USA; ${ }^{2}$ Division of Gastroenterology and Hepatology, Department of Internal Medicine, University of Iowa, Iowa City, IA, USA; \\ ${ }^{3}$ Department of Internal Medicine, University of Alabama, Birmingham, AL, USA; ${ }^{4}$ Genomic Medicine Institute, Cleveland Clinic \\ Foundation, Cleveland, OH, USA; ${ }^{5}$ Division of Gastroenterology and Hepatology, University of Alabama, Birmingham, AL, USA
}

\section{Abstract}

Background and Aims: Patatin-like phospholipase domain protein 3 (PNPLA3) polymorphisms (rs738409 C>G) are associated with non-alcoholic fatty liver disease (NAFLD). We performed a systematic review and meta-analysis to examine the association of PNPLA3 polymorphisms with the spectrum and severity of this disease. Methods: Studies evaluating the association between the PNPLA3 polymorphism spectrum (fatty liver, steatohepatitis, cirrhosis, and hepatocellular carcinoma) and NAFLD were included. Pooled data are reported as odds ratios (ORs) with 95\% confidence intervals. Results: Of 393 potentially relevant studies, 35 on NAFLD were included in the analysis. Compared to healthy controls, the pooled ORs for rs738409 CG and GG compared to $\mathrm{CC}$ among patients with non-alcoholic fatty liver (NAFL) were $1.46(1.16-1.85)$ and $2.76(2.30-3.13)$, and were 1.75 (1.24-2.46) and 4.44 (2.92-6.76) among patients with non-alcoholic steatohepatitis respectively. The respective ORs for CG and GG compared to the CC genotype were 2.35 (0.90-6.13) and 5.05 (1.47-17.29) when comparing nonalcoholic hepatocellular carcinoma to NAFL patients. Among the NAFLD patients, the ORs for $\mathrm{G}$ allele frequency when comparing steatosis grade $2-3$ to grade $0-1$ NAFL, when comparing the NAFLD activity score of $\geq 4$ to score $\leq 3$, when comparing NASH to NAFLD, when comparing the presence of lobular inflammation to absence, and when comparing the presence of hepatocyte ballooning to absence were $2.33(1.43-3.80), 1.80(1.36-2.37), 1.66$ (1.42-1.94), $1.58(1.19-2.10)$, and $2.63(1.87-3.69)$ respectively. Subgroup analysis based on ethnicity showed similar results. Conclusions: PNPLA3 polymorphisms have strong association

Keywords: PNPLA3; Polymorphisms; Non-alcoholic liver disease; rs738409 C>G. Abbreviations: ALD, alcoholic liver disease; BMI, body mass index; CRN, clinical research network; FL, fatty liver; HCC, hepatocellular carcinoma; HWE, HardyWeinberg equilibrium; ICAM-1, intercellular adhesion molecule 1 ; MOOSE, Metaanalysis Of Observational Studies in Epidemiology; NAC, non-alcoholic cirrhosis; NAHCC, non-alcoholic hepatocellular carcinoma; NAFL, non-alcoholic fatty liver; NAFLD, non-alcoholic fatty liver disease; NAS, NAFLD activity score; NASH, nonalcoholic steatohepatitis; OR, odds ratio; PNPLA3, patatin-like phospholipase domain protein 3.

Received: 15 March 2016; Revised: 10 May 2016; Accepted: 23 May 2016 DOI: $10.14218 / \mathrm{JCTH} .2016 .00009$.

*Correspondence to: Ashwani Kumar Singal, Division of Gastroenterology and Hepatology, University of Alabama, $18087^{\text {th }}$ Ave S BDB 351, Birmingham, AL 35294-0012, USA. Tel: +1-205-934-5623, Fax: +1-205-975-0961, E-mail: ashwanisingal.com@gmail.com with the risk for and severity of NAFLDs. PNPLA3 polymorphism plays an evolving role in diagnosis and treatment decisions in patients with NAFLD.

(C) 2016 The Second Affiliated Hospital of Chongqing Medical University. Published by XIA \& HE Publishing Inc. All rights reserved.

\section{Introduction}

Non-alcoholic fatty liver disease (NAFLD) is one of the most common causes of liver cirrhosis and end-stage liver disease in the US, behind hepatitis $C$ virus infection and alcoholic liver disease (ALD) ${ }^{1,2}$ Within the past few years, multiple genetic factors have been associated with the severity and predisposition to the spectrum of NAFLDs, including the associated increased risk of hepatocellular carcinoma (HCC). ${ }^{3}$ Recently, the single nucleotide polymorphism rs738409 $C>G$ (causing an isoleucine to methionine substitution at position 148 , $\mathrm{I} 148 \mathrm{M})$ in the patatin-like phospholipase domain containing protein 3 (PNPLA3) gene has been shown to be associated with steatosis among NAFLD patients. ${ }^{3}$ Since then, other genetic polymorphisms of this gene have been shown to be associated with various other liver diseases, including ALD. ${ }^{4}$ In vitro, the human adiponutrin (another name for the PNPLA3 gene product) exhibits activity as a triglyceride hydrolase and transacylase, as well as modest activity as a calcium-independent phospholipase A2. However, in the cellular context, these activities appear minor; similarly, overexpression or knockdown of adiponutrin did not affect lipolysis or the cellular TG level. ${ }^{5,6}$

We have shown previously that PNPLA3 is associated with ALD and its severity spectrum (including fatty liver (FL), steatohepatitis, cirrhosis, and HCC). ${ }^{4}$ ALD and NAFLD share several histological features and pathophysiologic mechanisms, including oxidative and endoplasmic reticulum-mediated stress, gut derived endotoxin-mediated cytokine release, and mitochondrial defects. ${ }^{7}$ Over the last 5 years, meta-analyses of pooled data on the associations between the PNPLA3 gene and risk of NAFLD have been reported. ${ }^{8-10}$ However, given that these previous meta-analyses were limited and did not examine the association of this genetic polymorphism with the entire spectrum of liver disease-from FL and steatohepatitis to fibrosis, cirrhosis, and HCC-amongst NAFLD patients, we performed the meta-analysis presented herein, with the aim of examining the association of PNPLA3 polymorphisms 
with the predisposition to and severity of the whole spectrum of liver disease among patients with NAFLDs.

\section{Methods}

\section{Identification and retrieval of primary studies}

Following the Meta-analysis Of Observational Studies in Epidemiology (MOOSE) guidelines, we searched the literature from the PubMed/Medline, Embase and Cochrane search engines to identify full-length articles written in English that examined PNPLA3 polymorphism in NAFLD patients. ${ }^{11}$ The initial search terms were "non-alcoholic fatty liver disease" and "adiponutrin, human". The search was then expanded to include the terms "rs738409 C> G" and "patatin-like phospholipase domain-containing 3 protein". All databases were searched from their inception through April 2016. Meeting abstracts from major gastroenterology conferences within the past 4 years were also searched to identify studies that were potentially missed by our database searches. Articles were selected for full-text review based on initial reading of the title and abstract. Manual search of the retrieved publications was done by three independent investigators (HS, MM, and $M A$ ) to avoid missing articles and ensure as comprehensive search of the literature as possible.

\section{Inclusion and exclusion criteria}

Studies reporting association of the PNPLA3 variant (rs738409 $C>G$ ) among NAFLD patients and published as full-length articles were eligible for inclusion in this analysis. Studies on patients with other liver diseases but reporting separate data on PNPLA3 polymorphisms for NAFLD were also eligible for inclusion. However, studies without available gene frequency data for analysis and studies including subjects with other liver diseases and without separate data on NAFLD patients were excluded.

\section{Definitions}

The disease spectrum across studies on NAFLD patients was defined as non-alcoholic fatty liver (NAFL) according to: steatosis on liver ultrasound in the absence of elevated liver enzymes and/or histologic evidence of steatohepatitis or nonalcoholic steatohepatitis (NASH); steatosis with histologic evidence of steatohepatitis or non-alcoholic cirrhosis (NAC); biopsy or clinical evaluation supported by hematological, biochemical, and/or radiologic imaging findings, and presence of non-alcoholic hepatocellular carcinoma (NAHCC); diagnostic imaging findings on tripleOphase magnetic resonance imaging or computed tomography or using histological confirmation from the liver tissue. Healthy controls were defined as subjects without liver disease, for the whole spectrum of NAFLD.

\section{Study selection and data extraction}

After determining the eligibility for inclusion, three reviewers (HS, MM, and MA) independently extracted data for (a) study characteristics (author and year of publication, and study design (population-based or not, using controls or not)), (b) study population (liver disease spectrum and the sample size), (c) frequencies of PNPLA3 polymorphism genotypes (rs738409 CC, CG, and GG), and (d) odds ratio (OR; for association of PNPLA3 polymorphism and the spectrum of liver disease and for severity of liver disease). Any discrepancy between the reviewers was resolved by jointly reviewing the study in question. Among studies comparing a diseased population with healthy controls, similar data was also extracted for the healthy controls.

\section{Endpoints and outcomes}

Our study endpoints for analysis on the data from included NAFLD studies were risks of (a) entire spectrum of liver disease compared to healthy controls and (b) severity of liver disease spectrum among the NAFLD diseased population.

\section{Assessment of study quality}

The quality of included studies was assessed independently by three authors (HS, MM, and MA) using the NewcastleOttawa Quality Assessment Scale for case-control studies. ${ }^{12}$ This scale has one instrument for assessing case-control studies and another one for cohort studies. Each of these instruments includes measures of quality in selection, comparability, and exposure domains. While one point is granted for each of the areas measured within the selection and exposure domains, a maximum of two points can be assigned within the comparability domain with highest possible total score of nine. A score of seven or greater denotes a highquality study. Any discrepancies between the three coauthors were addressed by a joint reevaluation of the original article. ${ }^{13}$

Since deviation from Hardy-Weinberg equilibrium (HWE) in healthy controls has been associated with problems in the design and conduct of genetic association studies, ${ }^{14,15}$ we examined the studies on the gene allele frequencies of healthy controls for any deviation from HWE. HWE analysis on gene frequencies among healthy controls was examined using the chi-square test, with the value of $<3.84$ indicating allele frequency to be in HWE.

\section{Statistical analysis}

The strength of association between rs738409 $C>G$ and NAFLD prevalence was expressed by OR and the corresponding $95 \%$ confidence interval (CI). Random effects modeling was used for analyzing the pooled data for all the analyses. ${ }^{16}$ Heterogeneity was measured using the $I^{2}$ statistic for interstudy variance, with the chi-square test used for statistical analysis. ${ }^{17}$ Heterogeneity was defined with $I^{2} \geq 50 \%$ or chisquare $p<0.10 .{ }^{17}$ At least two studies are needed to examine and report heterogeneity; in our investigations of heterogeneous data and the source of heterogeneity, sensitivity analyses were performed in a stepwise fashion for (a) study quality, (b) excluding studies on the pediatric population for NAFLD analyses, and (c) excluding studies with highest and lowest OR. Publication bias was assessed using Egger's regression and the Begg and Mazumdar's rank correlation tests. ${ }^{18-20}$ Egger's test is a regression method that evaluates the association between effect sizes and standard error and uses actual effect size for each study. ${ }^{20}$ Begg and Mazumdar's test is a rank correlation test that evaluates the association between effect estimates (taken as a rank and not exact effect size) and sampling variance or standard error. ${ }^{19}$ At least three studies are needed for examining and reporting publication bias; in our analyses of publication bias, the analyses were 


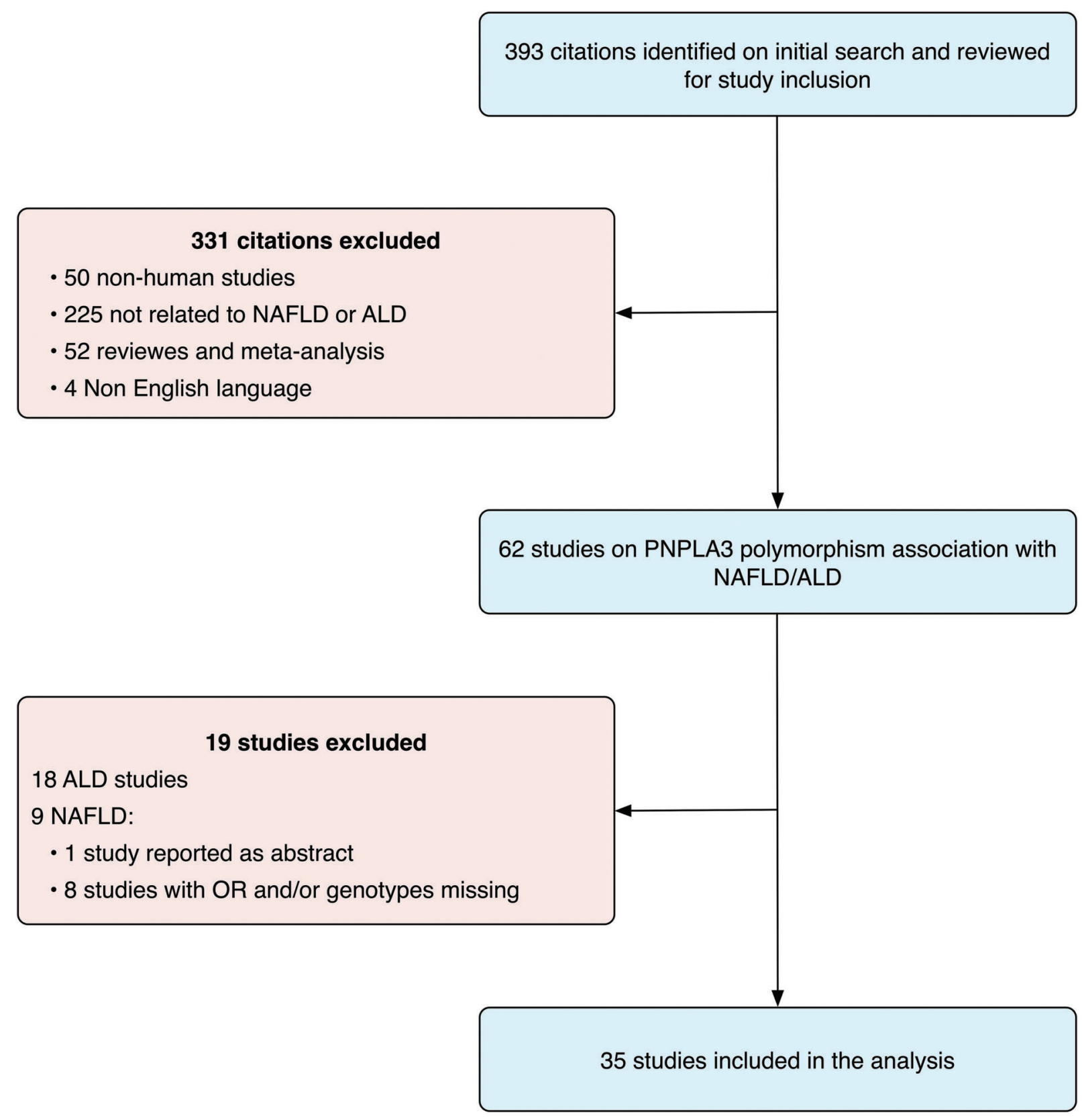

Fig. 1. Literature search and study inclusion.

repeated using the Duval and Tweedie trim-and-fill method, a nonparametric (rank-based) data augmentation technique. ${ }^{21}$ Most extreme results on one side of the funnel plot are suppressed and this tool used to estimate the number of studies missing from a meta-analysis. Subsequently, it augments the observed data so that the funnel plot is more symmetric and re-computes the summary estimate based on the complete data. ${ }^{22}$ This method should be regarded as a way of examining the sensitivity of the results to one particular selection mechanism rather than a way of yielding a more "valid" estimate of the overall effect or outcome. To examine the effect of ethnicity on the association of rs738409 with NAFLD, subgroup analysis was performed by grouping studies with similar populations. All statistical analyses were performed using $\mathrm{R}$ software (Foundation for Statistical Computing, Stanford, CA, USA) and its associated metaphor package, or Comprehensive Meta-analysis software (Biostat, Englewood, NJ, USA).

\section{Results}

\section{Baseline study characteristics}

Of the 393 citations retrieved by the initial search, 462 were reviewed with full-text reading (Fig. 1). Among these, 27 studies were excluded for including patients with ALD $(n=18)$ and 


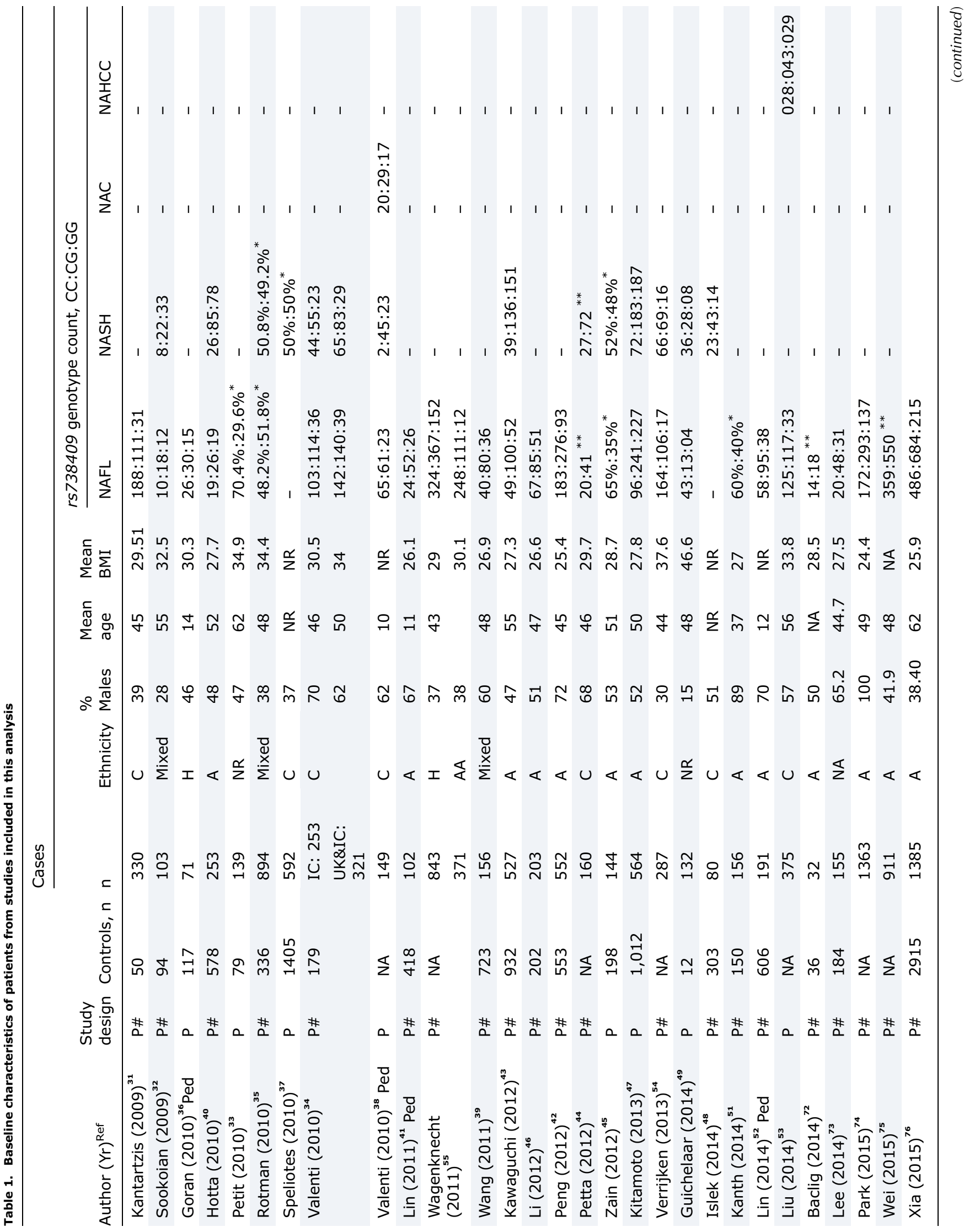




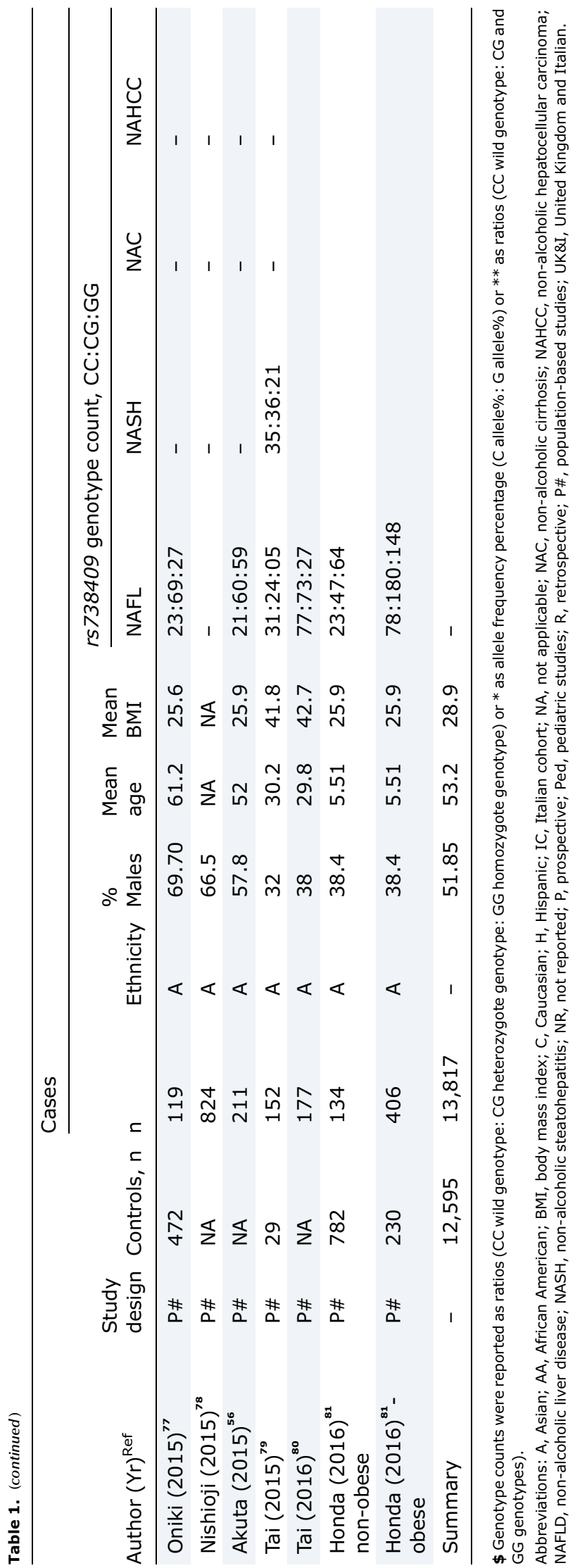

other reasons ( $n=9),{ }^{3,23-30}$ including 5 studies due to unavailability of needed data for analysis and 4 studies published as abstracts. The included 35 studies encompassed a total of 13,817 patients (mean age of $52 \mathrm{yrs}, 53 \%$ male, mean body mass index (BMI) of 29) and reported on PNPLA3 polymorphisms data in NAFLD (Table 1). ${ }^{31-55}$ Based on the Newcastle-Ottawa scale, 23 NAFLD studies were of high quality, with study quality score of 7 or more, and the remaining 12 studies were of poor quality (Table 2). Twenty-five studies had control populations. ${ }^{31-37,39-43,45-52}$ Genotype frequency (to perform HWE analysis in healthy controls) was available for only 19 of the studies (Table 3); among these, the control population in only one study deviated from HWE. ${ }^{31}$

\section{PNPLA3 polymorphisms in NAFLD compared to healthy controls}

NAFL

Among the 26 included studies on 10,236 NAFLD patients, the pooled ORs for rs738409 C> -CG and GG- genotypes compared to the CC genotype in NAFL patients were 1.46 (1.16-1.85) and $2.76(2.30-3.13)$ respectively (Fig. 2A, 2B). The data were heterogeneous for the CG analysis but not for the GG analysis, with respective values of $I^{2}=67.4 \%, p<0.0001$ and $I^{2}=27.9 \%, p=0.16$. No publication bias was found by Egger's test $(p=0.14$ and 0.28$)$ or Begg and Mazumdar's test $(p=0.63$ and 0.74$)$. The pooled OR for $G$ allele frequency for NAFL compared to healthy controls was 1.91 (1.64-2.21) (Fig. 2C), with heterogeneous data $\left(I^{2}=72.6 \%, p<0.0001\right)$ and publication bias (by Egger's test, $p=0.0023$; by Begg and Mazumdar's test, $p=0.009)$. Sensitivity analysis using the trim-and-fill method showed homogeneous data, with similar effect size of 1.65 (1.55-1.77).

Among studies of Asian populations, the pooled ORs for the CG ( 8 studies with 2,610 patients) and GG (10 studies with 2,748 patients) genotypes as compared to the CC genotype were $1.50(1.13-2.00)$ and $2.67(2.16-3.31)$ respectively. The data were heterogeneous for the CG analysis $\left(I^{2}=70 \%, p=0.001\right)$ and homogeneous for the GG analysis $\left(I^{2}=32 \%, p=0.15\right)$. No publication bias was found by Egger's test ( $p=0.17$ and 0.59 ) or Begg and Mazumdar's test $(p=0.27$ and 1.0). Similarly, among studies of Caucasian populations, the pooled ORs for the CG ( 2 studies with 904 patients) and GG (2 studies with 904 patients) genotypes as compared to the CC genotype were $1.29(0.29-3.49)$ and $3.51(2.00-6.14)$ respectively. The data were heterogeneous for both analyses $\left(I^{2}=84 \%\right.$, $p=0.01$ and $\left.I^{2}=89 \%, p<0.0001\right)$; however, publication bias could not be assessed, as there were only two studies in each analysis. The pooled OR for the $G$ allele frequency in 12 Asian studies with 5,319 patients was 1.78 (1.52-2.08), with heterogeneous data $\left(I^{2}=70, p<0.0001\right)$ and publication bias as assessed by Egger's test $(p=0.04)$ but not by Begg and Mazumdar's test $(p=0.12)$. Other ethnicities (Caucasians, Blacks, and Hispanics) were reported in one study each (Table 4). Combined analysis on the non-Asian population for the $\mathrm{G}$ allele frequency was 3.29 (1.89-5.54), with homogenous data $\left(I^{2}=51, p=0.13\right)$ and no publication bias (Egger's test, $p=0.37$; Begg and Mazumdar's test, $p=0.5)$. 
Salameh H. et al: PNPLA3 polymorphisms and non-alcoholic liver disease

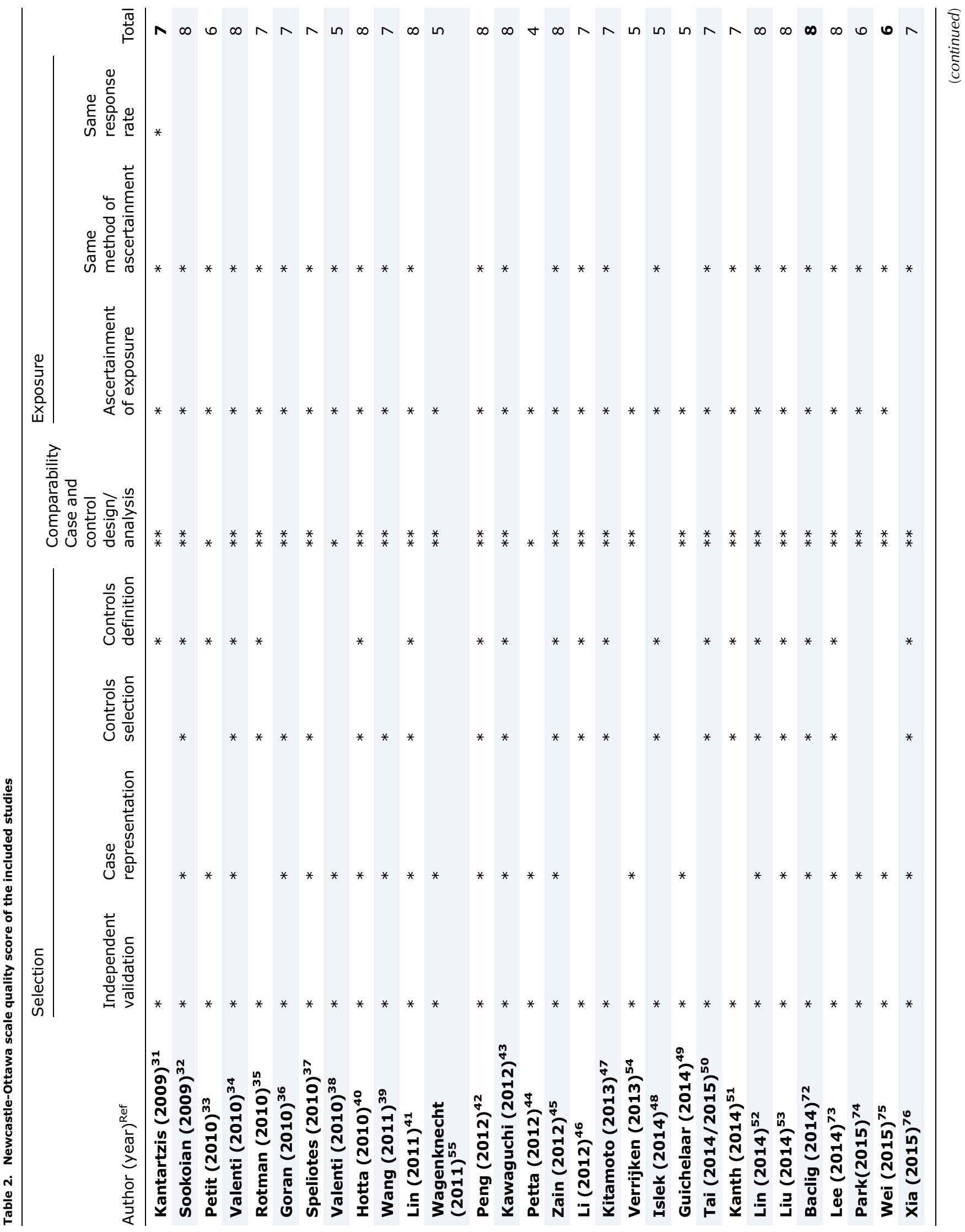




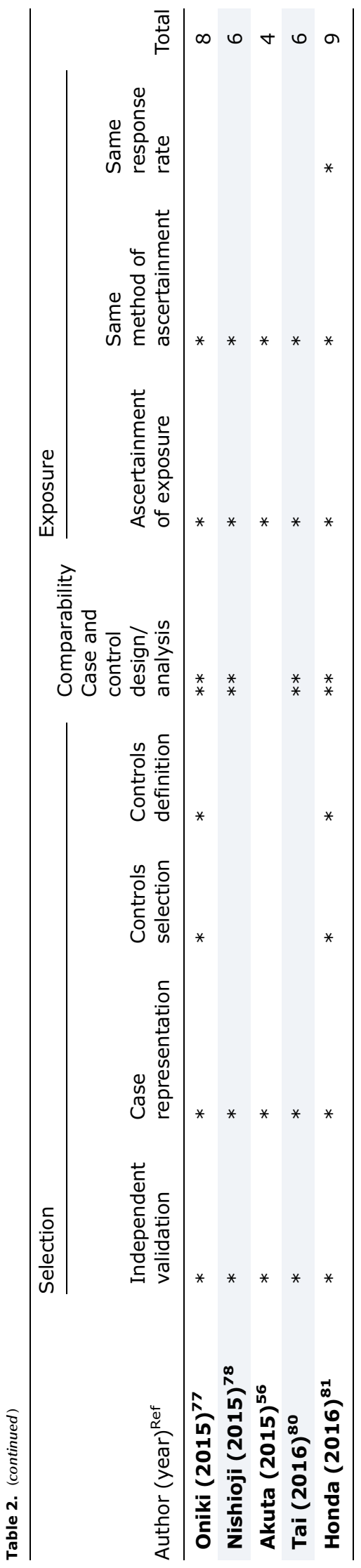

$\mathrm{NASH}$

For the two studies on 353 NAFLD patients, the pooled ORs for the rs738409 C>G -CG and GG- genotypes compared to the CC genotype for presence of NASH were 1.75 (1.24-2.46) and $4.44(2.92-6.76)$ respectively (Fig. 3A, 3B). The data were very robust for both analyses, with respective values of $I^{2}=0 \%, p=0.55$ and $I^{2}=0 \%, p=0.38$. The Pooled OR for the $G$ allele frequency from five studies with 1,596 NASH patients was $2.54(2.03-3.16)$ (Fig. 3C). The data were heterogeneous $\left(I^{2}=67 \%, p=0.019\right)$ and there was no publication bias (Egger's test, $p=0.56$; Begg and Mazumdar's test, $p=0.5$ ). Ethnicity-based analysis among the 3 Asian studies encompassing 924 patients showed similar effect size of 2.25 (1.94-2.61), with homogeneous data $\left(I^{2}=0 \%, p=0.73\right)$. In additional, two Caucasian studies encompassing 672 patients showed an effect size was 3.20 (2.72-3.75), with homogeneous data $\left(I^{2}=0 \%, p=0.45\right)$ (Table 4$)$.

\section{Association of PNPLA3 polymorphisms with the severity of NAFLD}

Steatosis grade $2-3$ vs. $0-1$

The ORs of the rs738409 C>G -CG and GG- genotypes compared to the CC genotype for NAFL grade $2-3$ vs. grade $0-1$ were $1.17(0.35-3.92)$ and $2.15(0.96-4.84)$ respectively (Fig. 4A, 4B). The data for the GG analysis were heterogeneous $\left(I^{2}=67.8 \%, p<0.045\right)$ and there was no publication bias (Egger's test, $p=0.61$; Begg and Mazumdar's test, $p=1.0$ ). After excluding the study with extremely high OR and wide $\mathrm{CI}$ effect size, the results remained similar, with OR of $1.64(1.10-2.46)$ and homogenous data $\left(I^{2}=8.9 \%\right.$, $p=0.30)$. The $\mathrm{OR}$ for the $\mathrm{G}$ allele frequency pooled from six studies encompassing 2,521 patients was $2.33(1.43-3.80)$ (Fig. 4C), with heterogeneous data $\left(I^{2}=86 \%, p<0.0001\right)$ and evidence of publication bias by Egger's test $(p=0.025)$ but not by Begg and Mazumdar's test $(p=0.13)$. Ethnicity based analysis for four Caucasian studies encompassing 1,475 patients showed the OR for the $G$ allele frequency to be 2.69 (1.27-5.69) (Table 4), with homogeneous data. However, after excluding one study on a pediatric population, $^{38}$ the pooled OR for the G allele frequency became 1.54 (1.19-1.98), with homogeneous data $\left(I^{2}=48.9 \%\right.$, $p=0.1$ ) and evidence of publication bias by the Egger's test $(p=0.019)$. Using the trim-and-fill method, the effect size remained unchanged at $2.33(1.43-3.80)$, without any publication bias.

\section{NASH in NAFLD}

The pooled ORs for presence of NASH among NAFLD patients from four studies encompassing 1,146 patients for the CG and GG genotypes compared to the CC genotype were 1.92 (1.43-2.57) and $3.53(2.02-6.15)$ respectively (Fig. 5A, 5B); the data were homogeneous, with respective values of $I^{2}=0 \%, p=0.51$ and $I^{2}=0 \%, p=0.8$. There was no publication bias for the CG analysis (Egger's test, $p=0.7$; Begg and Mazumdar's test, $p=1.0$ ). There was also no publication bias for either the CG or the GG analysis (Egger's test, $p=0.43$ and 0.2; Begg and Mazumdar's test, $p=1.0$ and 0.29). Ethnicity-based analysis was not performed, as all studies were carried out with Asian populations. The OR for the $\mathrm{G}$ allele frequency pooled from 10 studies encompassing 
Salameh H. et al: PNPLA3 polymorphisms and non-alcoholic liver disease

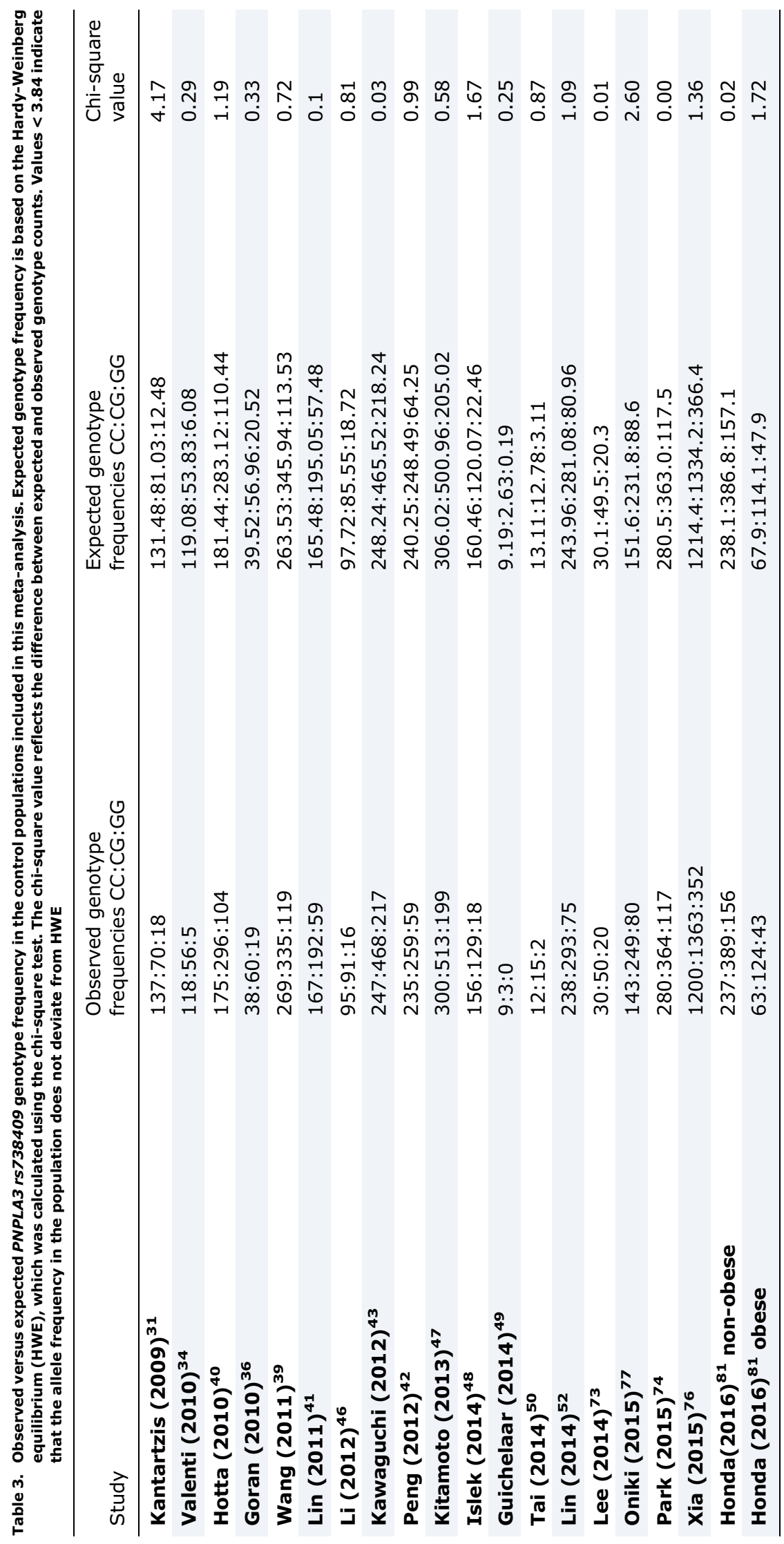


Salameh H. et al: PNPLA3 polymorphisms and non-alcoholic liver disease

\begin{tabular}{|c|c|c|c|c|c|c|}
\hline \multicolumn{7}{|c|}{ A } \\
\hline \multirow[t]{2}{*}{ Study name } & \multicolumn{3}{|c|}{ Statistics for each study } & \multicolumn{3}{|c|}{ Odds ratio and $95 \% \mathrm{Cl}$} \\
\hline & Odds ratio & Lower limit & Upper limit & & & \\
\hline Kantartzis 2009 & 2.150 & 1.186 & 3.897 & & - & \\
\hline Petit 2010 & 1.492 & 0.558 & 3.988 & & 1 & \\
\hline Valenti 2010 & 0.800 & 0.496 & 1.290 & . & & \\
\hline Wang 2011 & 1.550 & 1.021 & 2.353 & & II & \\
\hline Hotta 2011 & 0.810 & 0.439 & 1.496 & 1 & 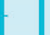 & \\
\hline Peng 2012 & 1.390 & 1.032 & 1.873 & & 4 & \\
\hline Kitamoto 2013 & 2.050 & 1.701 & 2.471 & & & \\
\hline Tai 2015 & 0.730 & 0.319 & 1.673 & 1 & - & \\
\hline Lin 2014 & 2.960 & 1.569 & 5.585 & & & I \\
\hline Oniki 2015 & 2.310 & 1.258 & 4.242 & & +1 & 1 \\
\hline Park 2015 & 1.640 & 1.190 & 2.260 & & -1 & \\
\hline \multirow[t]{2}{*}{ Tai 2016} & 0.710 & 0.308 & 1.638 & -1 & - & \\
\hline & 1.463 & 1.156 & 1.852 & & $\gamma$ & \\
\hline \multicolumn{7}{|l|}{ B } \\
\hline Kantartzis 2009 & 3.710 & 1.338 & 10.286 & & & $\square$ \\
\hline Goran 2010 & 4.700 & 2.388 & 9.252 & & & \\
\hline Valenti 2010 & 3.420 & 1.747 & 6.696 & & & 1 \\
\hline Wang 2011 & 2.030 & 1.226 & 3.360 & & & - \\
\hline Hotta 2011 & 1.680 & 0.850 & 3.320 & & & - \\
\hline Peng 2012 & 2.250 & 1.464 & 3.459 & & & - \\
\hline Bhatt 2013 & 1.980 & 1.433 & 2.736 & & & \\
\hline Tai 2015 & 2.360 & 0.497 & 11.214 & & & 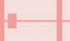 \\
\hline Lin 2014 & 5.840 & 2.591 & 13.164 & & & \\
\hline Oniki 2015 & 2.830 & 1.310 & 6.112 & & & 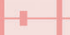 \\
\hline Park 2015 & 2.810 & 1.868 & 4.226 & & & $1-$ \\
\hline Таi 2016 & 2.310 & 0.483 & 11.058 & & & 1 \\
\hline Honda 2016 NO & 4.150 & 2.679 & 6.428 & & & $\rightarrow$ \\
\hline \multirow[t]{2}{*}{ Honda 2016 O } & 2.760 & 1.769 & 4.307 & & & $1-$ \\
\hline & 2.757 & 2.295 & 3.313 & & & 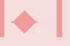 \\
\hline \multicolumn{7}{|l|}{ C } \\
\hline Kantartzis 2009 & 2.380 & 1.359 & 4.167 & & - & + \\
\hline Soonkoian 2009 & 2.800 & 1.504 & 5.213 & & & + \\
\hline Wegenknecht 2010 & 2.966 & 1.902 & 4.625 & & & 1 \\
\hline Wegenknecht 10 & 9.706 & 2.784 & 33.839 & & & 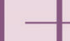 \\
\hline Wang 2011 & 1.440 & 1.120 & 1.851 & & + & \\
\hline Hotta 2011 & 1.370 & 0.879 & 2.136 & & $H$ & \\
\hline Peng 2012 & 1.770 & 1.295 & 2.419 & & -4 & - \\
\hline Kawaguchi 2012 & 1.660 & 1.425 & 1.933 & & + & \\
\hline Zain 2012 & 1.370 & 0.778 & 2.413 & & + & $t$ \\
\hline Zain 2012 & 2.230 & 1.600 & 3.109 & & & 1 \\
\hline Li 2012 & 1.730 & 1.497 & 1.999 & & & \\
\hline Kanth 2014 & 9.860 & 3.847 & 25.271 & & & \\
\hline Lin 2014 & 1.407 & 1.115 & 1.776 & & + & \\
\hline Tai 2016 & 1.160 & 0.658 & 2.044 & & 1 & \\
\hline Baclig 2014 & 31.210 & 0.899 & 1083.646 & & & \\
\hline Lee 2014 & 1.990 & 1.204 & 3.290 & & - & - \\
\hline Nishoji 2015 & 1.980 & 1.285 & 3.051 & & - & E \\
\hline Wei 2015 & 4.370 & 2.448 & 7.802 & & & - \\
\hline \multirow[t]{2}{*}{ Xia 2015} & 1.360 & 1.192 & 1.552 & & +1 & \\
\hline & 1.905 & 1.639 & 2.213 & & & - \\
\hline
\end{tabular}

Fig. 2. Forest plots for analysis of non-alcoholic fatty liver studies comparing patients to healthy controls for association of PNPLA3 polymorphisms with non-alcoholic fatty liver: A) CG vs. CC, B) GG vs. CC, and C) G allele. The bottom line in the "statistics for each study" represents the pooled effect size that was analyzed using the random effects model. An $\mathrm{OR}>1$ denotes risk for the respective outcome or positive association and an $\mathrm{OR}<1$ indicates a protective effect or negative association. A 95\% confidence interval not crossing 1 indicates a significant association. NO, non-obese; O, obese. 
A

Study name

Hotta 2011

Islek 2014

B

Hotta 2011

Islek 2014

C

Speliotes 2010

Hotta 2011

Kawaguchi $2012 \mathrm{~N}$

Zain 2012

Islek 2014
Statistics for each study

Odds ratio Lower limit Upper limit

$\begin{array}{lll}1.930 & 1.197 & 3.112 \\ 1.568 & 0.956 & 2.572 \\ 1.746 & 1.238 & 2.462\end{array}$

5.050

3.043

8.379

3.359

1.590

7.096

4.442

2.921

6.757

$\begin{array}{lll}3.260 & 2.760 & 3.850 \\ 2.000 & 1.332 & 3.004 \\ 2.180 & 1.808 & 2.628 \\ 2.580 & 1.802 & 3.694 \\ 2.630 & 1.542 & 4.486 \\ 2.535 & 2.032 & 3.163\end{array}$

\section{Odds ratio and $95 \% \mathrm{Cl}$}
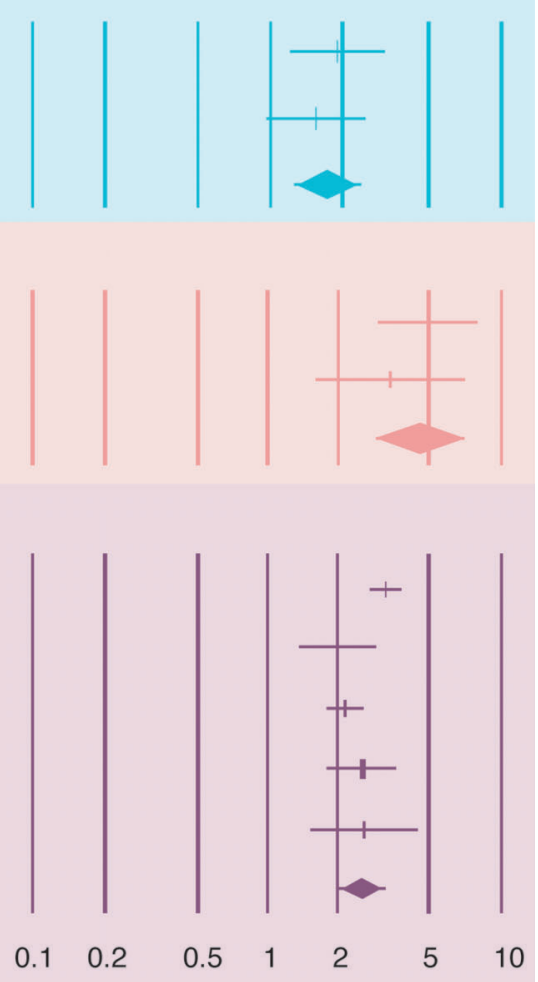

Fig. 3. Forest plots for analysis of non-alcoholic fatty liver studies comparing patients to healthy controls for association of PNPLA3 polymorphisms with non-alcoholic steatohepatitis: A) CG vs. CC, B) GG vs. CC, and C) G allele frequency. The effect size is reported as odds ratio with $95 \%$ confidence interval. The bottom line in the "statistics for each study" represents the pooled effect size that was analyzed using the random effects model. An OR $>1$ denotes risk for the respective outcome or positive association and an OR $<1$ indicates a protective effect or negative association. A 95\% confidence interval not crossing 1 indicates a significant association.

2,814 patients was $1.66(1.24-1.94)$ (Fig. 5C). The data were homogenous $\left(I^{2}=21.4 \%, p=0.24\right)$ and there was no publication bias (Egger's test, $p=0.096$; Begg and Mazumdar's test, $p=0.15)$. Ethnicity-based analysis showed that the OR for the $\mathrm{G}$ allele frequency in three Caucasian studies encompassing 1,326 patients was $1.42(1.01-2.00)$ and in five Asian studies was 1.84 (1.53-2.21); the data were homogenous for both analyses, with respective values of $I^{2}=54 \%, p=0.11$ and $I^{2}=0 \%, p=0.29$. In addition, there was no publication bias in either analysis (Egger's test, $p=0.39$ and 0.29; Begg and Mazumdar's test, $p=0.30$ and 0.46 ). One study reported data in a population of mixed ethnicities, without separate ethnicity-based data. ${ }^{32}$

NAFLD activity score and histopathologic severity

\section{NAS}

The pooled OR for the G allele frequency in the presence of NAS $>4$ vs. < 3 among NAFLD patients from four studies encompassing 1,586 patients was $1.80(1.36-2.37)$ (Fig. $6 \mathrm{~A})$; the data were homogenous $\left(I^{2}=19.8 \%, p=0.12\right)$ and there was no publication bias (Egger's test, $p=0.12$; Begg and
Mazumdar's test, $p=0.31$ ). However, after excluding a study that used a population of mixed ethnicities, ${ }^{35}$ the OR from the three Asian studies, now encompassing 692 patients, was 2.05 (1.35-3.12), with no publication bias (Egger's test, $p=0.32$; Begg and Mazumdar's test, $p=1.0)$.

\section{Lobular Inflammation}

The pooled OR for the $G$ allele frequency for the presence of lobular inflammation in five studies encompassing 2,313 patients was $1.58(1.19-2.10)$ (Fig. $6 \mathrm{~B})$; the data were heterogeneous $\left(I^{2}=56.9 \%, p=0.054\right)$ and there was no publication bias (Egger's test, $p=0.46$; Begg and Mazumdar's test, $p=0.46$ ). Ethnicity-based analysis (Table 4 ) showed that the OR for the G allele frequency in two studies of Caucasian populations encompassing 879 patients was 1.47 (1.19-1.83) and in two studies of Asian populations encompassing 540 patients was $1.72(0.52-5.69)$. The data were homogenous in the Caucasian analysis $\left(I^{2}=0 \%, p=0.40\right)$ but not in the Asian analysis $\left(I^{2}=84 \%, p=0.012\right)$. No analysis of publication bias was performed, as only two studies were included in each analysis. 
Salameh H. et al: PNPLA3 polymorphisms and non-alcoholic liver disease

Table 4. Ethnicity-based analysis on the association between PNPLA3 and risk for and severity of disease among NAFLD studies

\begin{tabular}{|c|c|c|c|c|c|}
\hline Comparison & Ethnicity & No. of studies & Genotypes & OR & $95 \% \mathrm{CI}$ \\
\hline \multirow[t]{9}{*}{ NAFL vs. controls } & Caucasians & 2 & CG vs CC & 1.29 & $0.29-3.49$ \\
\hline & Asians & 8 & & 1.50 & $1.13-2.00$ \\
\hline & Caucasians & 2 & GG vs CC & 3.51 & $2.00-6.14$ \\
\hline & Hispanics & 1 & & 4.70 & $2.39-9.25$ \\
\hline & Asians & 10 & & 2.67 & $2.16-3.31$ \\
\hline & Caucasians & 1 & G allele & 2.38 & $1.36-4.17$ \\
\hline & Blacks & 1 & & 9.71 & $2.78-33.84$ \\
\hline & Hispanics & 1 & & 2.97 & $1.90-4.80$ \\
\hline & Asians & 12 & & 1.78 & $1.52-2.08$ \\
\hline \multirow[t]{2}{*}{ NASH vs. controls } & Caucasian & 2 & G allele & 3.20 & $2.72-3.75$ \\
\hline & Asian & 3 & & 2.25 & $1.94-2.61$ \\
\hline \multirow[t]{2}{*}{ NAFL 2-3 vs. NAFL 0-1 } & Asian & 1 & G allele & 3.32 & $1.56-7.01$ \\
\hline & Caucasian & 4 & & 2.69 & $1.27-5.69$ \\
\hline \multirow[t]{2}{*}{ NASH vs. NAFL } & Caucasian & 3 & G allele & 1.42 & $1.01-2.00$ \\
\hline & Asian & 5 & & 1.84 & $1.53-2.21$ \\
\hline \multirow[t]{2}{*}{ NAFLD activity score } & Mixed & 1 & G allele & 1.56 & $1.12-2.17$ \\
\hline & Asian & 3 & & 2.05 & $1.35-3.12$ \\
\hline \multirow[t]{3}{*}{ Lobular inflammation } & Mixed & 1 & G allele & 1.84 & $1.33-2.55$ \\
\hline & Caucasian & 2 & & 1.47 & $1.19-1.83$ \\
\hline & Asian & 2 & & 1.72 & $0.52-5.69$ \\
\hline \multirow[t]{2}{*}{ Hepatocyte ballooning } & Caucasian & 2 & G allele & 3.17 & $2.68-3.76$ \\
\hline & Asian & & & 1.81 & $1.07-3.03$ \\
\hline \multirow[t]{2}{*}{ Fibrosis/Cirrhosis } & Caucasian & 2 & G allele & 1.41 & $1.13-1.74$ \\
\hline & Asian & 2 & & 2.16 & $1.90-2.58$ \\
\hline
\end{tabular}

Abbreviations: NAFL, non-alcoholic fatty liver; NAFLD, non-alcoholic fatty liver disease; NASH, non-alcoholic steatohepatitis.

\section{Hepatocyte ballooning}

The pooled $O R$ for the $G$ allele frequency for hepatocyte ballooning in four studies encompassing 1,419 patients was 2.63 (1.87-3.69) (Fig. 6C); the data were homogenous $\left(I^{2}=43.3 \%, p=0.15\right)$ and there was no publication bias (Egger's test, $p=0.24$; Begg and Mazumdar's test, $p=$ 0.31 ). Ethnicity-based analysis (Table 4 ) showed that the OR for the $G$ allele frequency in two studies of Caucasian populations encompassing 879 patients was 3.17 (2.68-3.76) and in two studies of Asian populations encompassing 540 patients was 1.81 (1.07-3.03). The data were homogeneous in both analyses $\left(I^{2}=0 \%, p=0.66\right.$ and $I^{2}=0 \%, p=0.32$ respectively)

\section{Portal inflammation}

Only one study encompassing 894 patients reported the OR of the $\mathrm{G}$ allele frequency for portal inflammation, and the value was 1.57 (1.24-1.99).

\section{Fibrosis and cirrhosis}

Among the eight studies of advanced cirrhosis and fibrosis encompassing 3,571 patients, the pooled ORs for the rs738409 C>G CG and GG genotypes compared to the CC genotype were 18.80 (2.12-166.75) (from one study ${ }^{56}$ ) and $2.72(0.84-8.83)$ respectively (Fig. $7 \mathrm{~A})$. The data were heterogeneous for the GG analysis $\left(I^{2}=76.8 \%, p=0.013\right)$ and there was no publication bias (Egger's test, $p=0.22$; Begg and Mazumdar's test, $p=0.29$ ). When the pediatric study ${ }^{38}$ was excluded, the pooled OR showed a similar effect size of $1.43(0.94-2.17)$. The data were homogenous $\left(I^{2}=0 \%\right.$, $p=0.61)$. The pooled OR for the $\mathrm{G}$ allele frequency was 1.67 (1.37-2.03) (Fig. 7B), with heterogeneous data $\left(I^{2}=55.9 \%\right.$, $p=0.045$ ) and no publication bias (Egger's test, $p=0.61$; Begg and Mazumdar's test, $p=1.0$ ). The pooled OR for the $\mathrm{G}$ allele frequency after excluding the pediatric study ${ }^{38}$ was 1.64 (1.32-2.04) (data not shown in figure form), with heterogeneous data $\left(I^{2}=64 \%, p=0.03\right)$ and no publication bias (Egger's test, $p=0.49$; Begg and Mazumdar's test, $p=1.0$ ). Ethnicity-based analysis showed that among two studies on Caucasian populations encompassing 1,166 patients the pooled OR for the G allele frequency was 1.41 (1.13-1.74), with homogeneous data $\left(I^{2}=0 \%, p=0.61\right)$, and among the two studies on Asian populations encompassing 682 patients the pooled $\mathrm{OR}$ for the $\mathrm{G}$ allele frequency was 2.16 (1.902.58), with homogeneous data $\left(I^{2}=0 \%, p=0.60\right)$ (Table 4$)$. 
A

Study name

$\begin{array}{lccc} & \text { Odds ratio } & \text { Lower limit } & \text { Upper limit } \\ \text { Tai 2014 } & 1.170 & 0.350 & 3.916 \\ & 1.170 & 0.350 & 3.916 \\ \text { B } & & & \\ \text { Honda 2016 NO } & 1.170 & 0.551 & 2.484 \\ \text { Honda 2016 O } & 1.860 & 1.210 & 2.860 \\ \text { Tai 2015 } & 9.940 & 2.202 & 44.870 \\ & 2.150 & 0.956 & 4.836 \\ \text { C } & & & \\ \text { Valenti 2010 } & & & \\ \text { Valenti 10 } & 1.350 & 1.038 & 1.756 \\ \text { Rotman 2010 } & 18.860 & 7.330 & 48.525 \\ \text { Speliotes 2010 } & 1.460 & 1.065 & 2.001 \\ \text { Petta 2012 } & 1.260 & 0.932 & 1.704 \\ \text { Tai 2014 } & 3.017 & 1.123 & 8.107 \\ & 3.320 & 1.560 & 7.068 \\ & 2.331 & 1.429 & 3.802\end{array}$

\section{Odds ratio and $95 \% \mathrm{Cl}$}
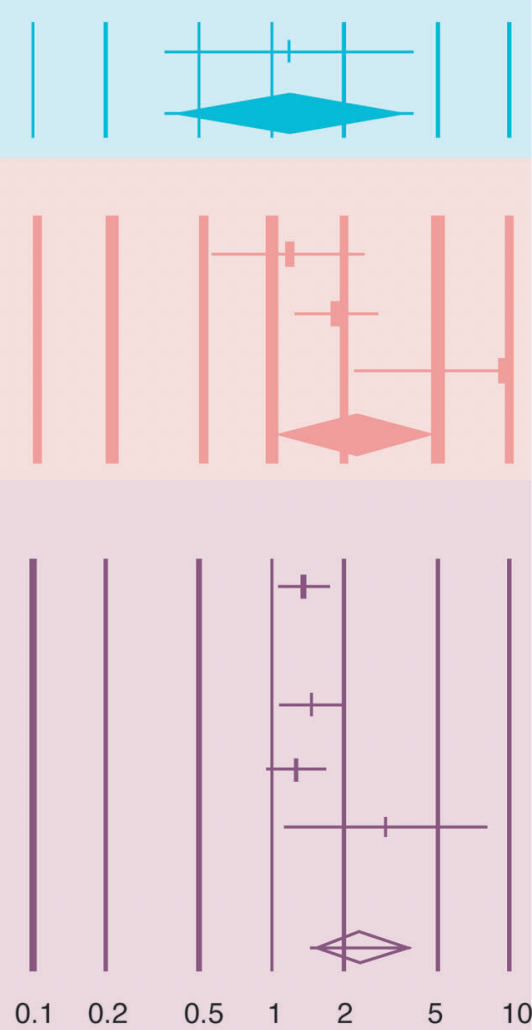

Fig. 4. Forest plots for analysis of the risk of spectrum of non-alcoholic fatty liver disease on the association of PNPLA3 polymorphism with steatosis grades 2-3 vs. 0-1: A) CG vs. CC, B) GG vs. CC, and C) G allele frequency. The bottom line in the "statistics for each study" represents the pooled effect size that was analyzed using the random effects model. An OR $>1$ denotes risk for the respective outcome or positive association and an OR $<1$ indicates a protective effect or negative association. A $95 \%$ confidence interval not crossing 1 indicates a significant association. NO, non-obese; 0 , obese. Valenti 10 refers to the pediatric study. ${ }^{38}$

\section{HCC in NAFLD}

The ORs of the rs738409 C>G -CG and GG- genotypes as compared to the CC genotype for the risk of NAHCC among NAFL patients without cirrhosis were $2.35(0.90-6.13)$ and 5.05 (1.47-17.29) respectively. The pooled OR of the rs738409 C>G CG as compared to the CC genotype for NAHCC among patients with NAC was 2.06 (1.07-3.94). All these analyses were reported in one study each, and the forest plots are not shown for these analyses. ${ }^{53}$

\section{Discussion}

This meta-analysis includes data for both adult and pediatric NAFLD, by which we demonstrate that PNPLA3 polymorphisms are associated with a) the risk of NAFL and NASH compared to healthy controls and $b$ ) more severe disease on the spectrum of NAFLD, where the polymorphism correlated with the grade of steatosis, NAS, histopathologic findings, cirrhosis and when NASH or NAHCC were compared to NAFL.

The PNPLA3 gene, a transmembrane protein encoding for adiponutrin in human, is highly expressed in the liver and adipose tissues. Its expression in subcutaneous and intra-abdominal adipose tissues correlates with obesity. ${ }^{57}$ The biochemical function of adiponutrin is uncertain, but it is considered to have lipogenic transacetylase activity, likely facilitating energy mobilization and lipid storage in adipose and liver tissues. ${ }^{57,58}$ Recently, it has been reported that the $148 \mathrm{M}$ adiponutrin allele is a loss-of function variant that predisposes an individual to steatosis by decreasing triglyceride hydrolysis in hepatocytes. ${ }^{59}$ However, this genetic variant does not appear to correlate with visceral or subcutaneous fat content, insulin sensitivity, or peripheral blood lipid levels. ${ }^{37,38}$ Consistent with the phenotype of NAFLD patients, overexpression of PNPLA3 G allele increases the size of lipid droplets, as compared with the overexpression of PNPLA3 C allele. ${ }^{60}$ The results of this meta-analysis are compatible with the mechanism of action of PNPLA3 and its presumed effect on liver toxicity. The exact mechanism by which PNPLA3 polymorphism increases the risk of HCC is yet to be determined. PNPLA3 was recently linked to increasing circulating levels of the intercellular adhesion molecule 1 (ICAM-1), ${ }^{61}$ which is a proinflammatory marker and characterized as a determinant of the malignant nature of tumors; ${ }^{62,63}$ in addition, it has been 
A

Study name

Hotta 2011

Kitamoto 2013

Tai 2015

Tai 2016

B

Hotta 2011

Tai 2015

Tai 2016

C

Sookoian 2009

Valenti 2010

Speliotes 2010

Hotta 2011

Kawaguchi 2012

Petta 2012

Zain 2012

Guichelaar 2014

Tai 2015

Tai 2016
Statistics for each study

Odds ratio Lower limit Upper limit

$\begin{array}{lll}2.390 & 1.142 & 5.000 \\ 2.210 & 1.459 & 3.348 \\ 1.330 & 0.658 & 2.690 \\ 1.490 & 0.728 & 3.051 \\ 1.917 & 1.429 & 2.572\end{array}$

3.000

1.381

6.516

3.720

1.251

4.790

1.480

3.525

2.020

15.501

6.149

Odds ratio and $95 \% \mathrm{Cl}$
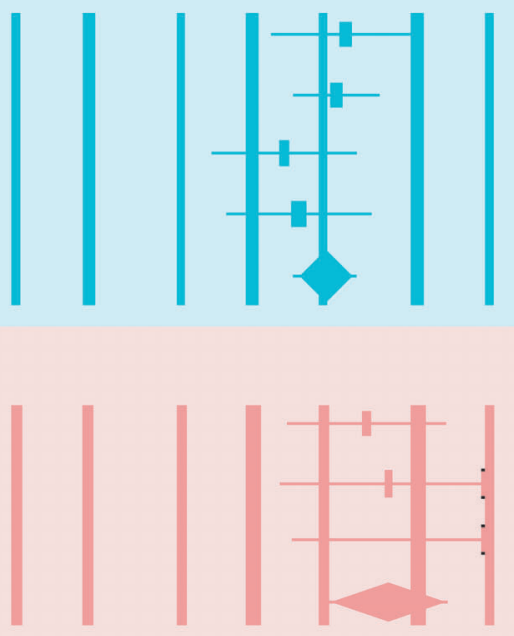

$\begin{array}{lll}1.880 & 1.030 & 3.431 \\ 1.500 & 1.111 & 2.024 \\ 1.140 & 0.860 & 1.511 \\ 1.650 & 1.082 & 2.515 \\ 1.960 & 1.468 & 2.617 \\ 3.064 & 1.107 & 8.480 \\ 1.630 & 0.943 & 2.818 \\ 2.430 & 1.116 & 5.291 \\ 1.860 & 1.137 & 3.042 \\ 1.930 & 1.181 & 3.153 \\ 1.656 & 1.417 & 1.935\end{array}$

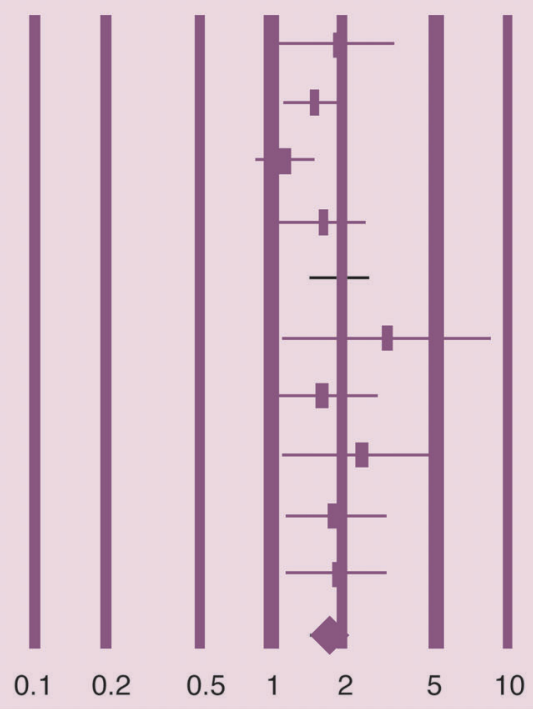

Fig. 5. Forest plots for analysis of the risk of spectrum of non-alcoholic fatty liver disease on the association of PNPLA3 polymorphism with non-alcoholic steatohepatitis vs. non-alcoholic fatty liver: A) CG vs. CC, B) GG vs. CC, and C) G allele frequency. The bottom line in the "statistics for each study" represents the pooled effect size that was analyzed using the random effects model. An OR $>1$ denotes risk for the respective outcome or positive association and an OR $<1$ indicates a protective effect or negative association. A $95 \%$ confidence interval not crossing 1 indicates a significant association.

shown to be associated with decreased levels of adiponectin, a protein with oncosuppressive properties. ${ }^{64}$

This is the first comprehensive meta-analysis examining the association of PNPLA3 polymorphisms with the risk for and severity of the spectrum of liver disease among NAFLD patients. The previous meta-analysis by $\mathrm{Xu}$ et $\mathrm{al}^{9}$ included 23 studies and looked at the association between NAFL/NASH and PNPLA3 polymorphism, but did not include NAHCC, NAC, steatosis grade, NAS, etc. The other most recent meta-analysis published in the literature investigated the association between NAFLD and PNPLA3 in studies of Asian populations only. ${ }^{10}$ Our current analysis included a total of 25 NAFLD studies and confirmed these findings, expanding our understanding of the associations with different liver disease phenotypes. In addition, we confirmed the HWE calculations when possible, looked at the study quality assessment based on the Newcastle-Ottawa scale, and performed subgroup analysis based on age and ethnicity to confirm our findings. All of these features of our study make the current analysis more comprehensive than the previous ones for gaining a more detailed understanding of the NAFLD and PNPLA3 genetic association. 
A

Study name

$\begin{array}{lccc} & \text { Odds ratio } & \text { Lower limit } & \text { Upper limit } \\ \text { Honda 2016 NO } & 2.420 & 1.087 & 5.386 \\ \text { Honda 2016 O } & 1.550 & 1.001 & 2.401 \\ \text { Rotman 2010 } & 1.560 & 1.121 & 2.171 \\ \text { Tai 2015 } & 2.960 & 1.512 & 5.796 \\ & 1.796 & 1.362 & 2.369 \\ \text { B } & & & \\ \text { Honda 2016 NO } & & & \\ \text { Honda 2016 O } & 3.370 & 1.428 & 7.951 \\ \text { Rotman 2010 } & 0.990 & 0.645 & 1.519 \\ \text { Speliotes 2010 } & 1.840 & 1.329 & 2.548 \\ \text { Verrjiken 2013 } & 1.420 & 1.126 & 1.790 \\ & 1.860 & 1.044 & 3.314 \\ \text { C } & 1.578 & 1.189 & 2.096 \\ \text { Honda 2016 NO } & & & \\ \text { Honda 2016 O } & & & \\ \text { Speliotes 2010 } & 2.510 & 1.092 & 5.770 \\ \text { Verriken 2013 } & 1.460 & 0.750 & 2.841 \\ & 3.210 & 2.689 & 3.832 \\ & 2.780 & 1.512 & 5.112 \\ & 2.626 & 1.871 & 3.686\end{array}$

\section{Odds ratio and $95 \% \mathrm{Cl}$}
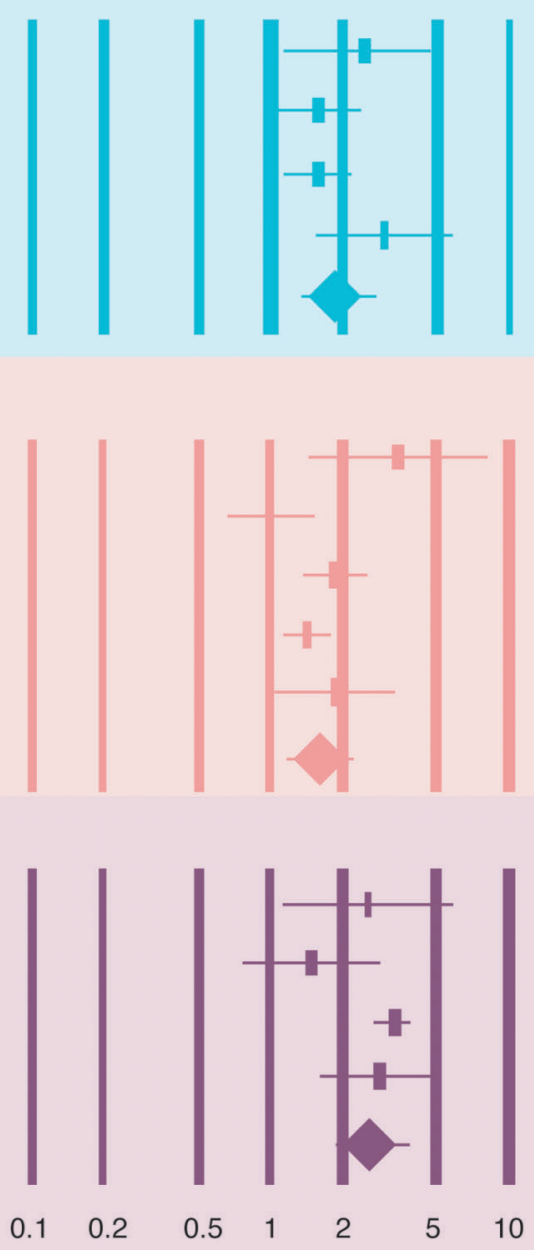

Fig. 6. Forest plots for analysis of the risk of spectrum of non-alcoholic fatty liver disease on the association of PNPLA3 polymorphism with $G$ allele frequency in NAFLD activity score in panel (A), in lobular inflammation in panel (B) and in hepatocyte ballooning in panel (C). The bottom line in the "statistics for each study" represents the pooled effect size that was analyzed using the random effects model. An OR $>1$ denotes risk for the respective outcome or positive association and an OR $<1$ indicates a protective effect or negative association. A 95\% confidence interval not crossing 1 indicates a significant association. NO, non-obese; O, obese.

Herein we present results from our meta-analysis of ten ALD studies, which also included individual participant data from five studies, showing that the PNPLA3 polymorphism was associated with predisposition to and severity of the ALD spectrum. ${ }^{4}$ When we compared the current meta-analysis with the previous one we noted certain differences between NAFLD and the ALD disease spectrum and the association with the PNPLA3 polymorphism. First of all, there is a stronger association amongst NAFLD, as compared to the ALD studies. This could be due to more studies published and analyzed with larger sample size for the current analyses. Secondly, the association was lacking with alcoholic FL but it was more prominent in the current study for association with NAFL. A similar prevalence of the polymorphisms in drinkers with $\mathrm{FL}$ and non-drinkers aligns well with the fact that the $\mathrm{FL}$ in alcoholics is a universal phenomenon in alcoholics and is reversible upon abstinence. ${ }^{65-67}$
Our study is potentially limited by the possibility of publication bias. In order to minimize this potential limitation, however, and to subsequently overestimate the true effect size due to negative studies' identification failure, ${ }^{68}$ we combined searches from the PubMed/Medline, Embase and Cochrane databases with manual searches. Unfortunately, we could not examine the association of PNPLA3 polymorphism with NAC and NAHCC compared to controls due to the lack of studies examining this association. Unavailability of individual patient data also precluded our ability to examine the impact of confounders such as age, sex, comorbidities, and BMI on the association with the PNPLA3 polymorphisms.

Another limitation to our study relates to the differences in the definition of NASH used across the studies included in this analysis. Bedossa et al $^{69}$ described various features of hepatic injury in $\mathrm{NASH}$, with the histological finding of lobular inflammation and hepatocyte ballooning being key findings. 


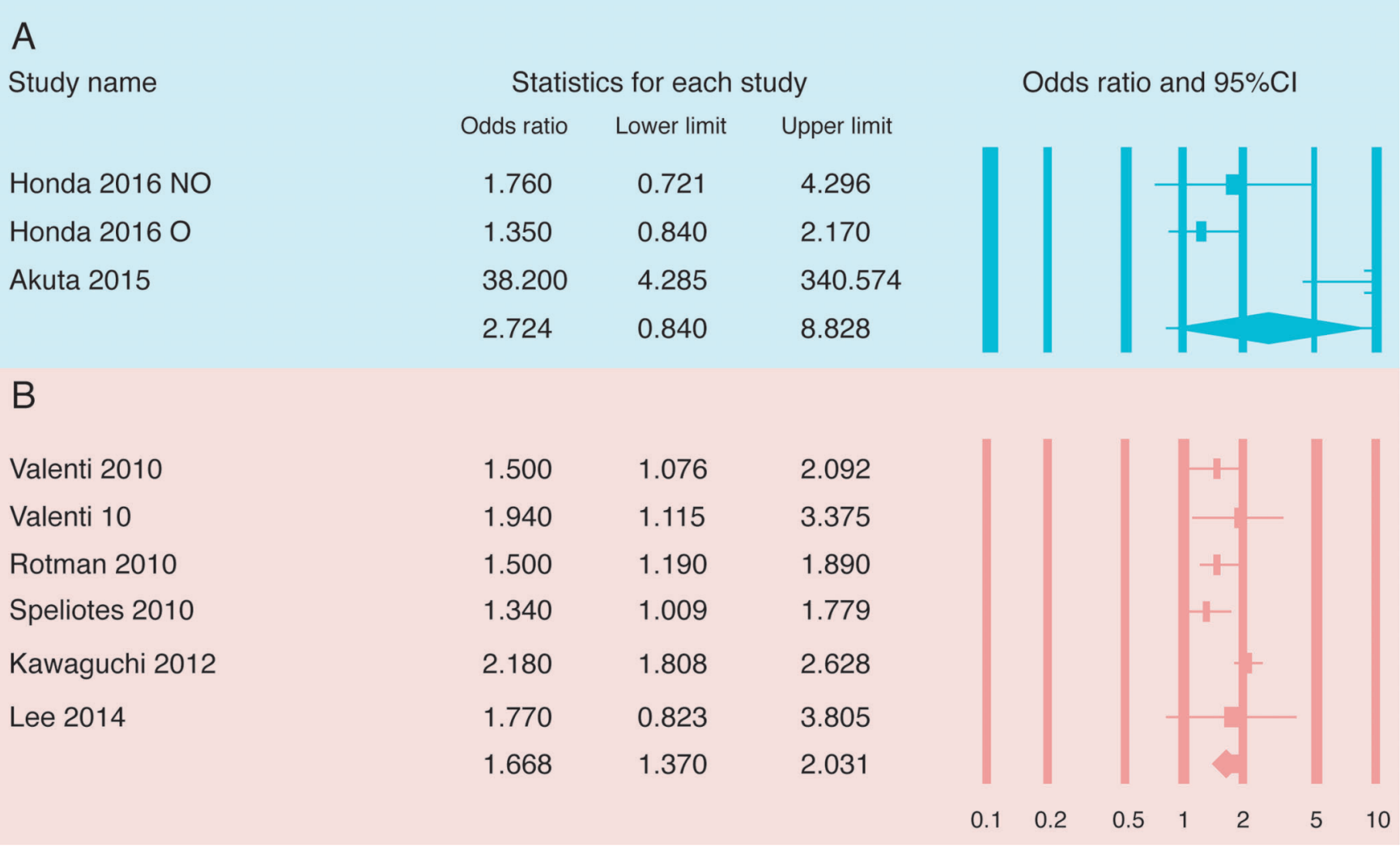

Fig. 7. Forest plots for analysis of the risk of spectrum of non-alcoholic fatty liver disease on the association of PNPLA3 polymorphism with fibrosis/ cirrhosis vs. NAFLD: A) GG vs CC, and B) G allele frequency. The bottom line in the "statistics for each study" represents the pooled effect size that was analyzed using the random effects model. An OR $>1$ denotes risk for the respective outcome or positive association and an OR $<1$ indicates protective effect or negative association. A $95 \%$ confidence interval not crossing 1 indicates a significant association. NO, non-obese; O, obese. Valenti 10 refers to the pediatric study. ${ }^{38}$

Different scoring systems were proposed, such as the Steatosis, Activity and Fibrosis system ${ }^{70}$ and the NASH Clinical Research Network system. ${ }^{71}$ To resolve this limitation, we grouped studies with almost similar definitions for the sake of homogeneity of the analysis.

In summary, the present study provided unequivocal evidence of rs738409 as a strong modifier of the natural history of NAFLD in different ethnic and age populations. As such, the PNPLA3 gene may be a potential target for therapy in NAFLD. Prospective data are now needed to further understand the association of PNPLA3 polymorphisms, particularly related to a) a response to control of risk factors of NAFLD and $b$ ) for prediction of the natural history of the disease.

\section{Conflict of interest}

None

\section{Author contributions}

Study design (HS, AKS), data collection (HS, MAH, MM, MN, $T M, A E)$, drafting the manuscript (HS, MAH, MM, MN, TM, AE, AKS), data analysis and interpretation (HS, AKS), critical revision and funding (AKS), statistical analysis (AKS, AE).

\section{References}

[1] Singal AK, Guturu P, Hmoud B, Kuo YF, Salameh H, Wiesner RH. Evolving frequency and outcomes of liver transplantation based on etiology of liver disease. Transplantation 2013;95:755-760. doi: 10.1097/TP.0b013e31827afb3a.

[2] Charlton MR, Burns JM, Pedersen RA, Watt KD, Heimbach JK, Dierkhising RA. Frequency and outcomes of liver transplantation for nonalcoholic steatohepatitis in the United States. Gastroenterology 2011;141:1249-1253. doi: 10.1053/j. gastro.2011.06.061.

[3] Kotronen A, Johansson LE, Johansson LM, Roos C, Westerbacka J, Hamsten A, et al. A common variant in PNPLA3, which encodes adiponutrin, is associated with liver fat content in humans. Diabetologia 2009;52:1056-1060. doi: 10. 1007/s00125-009-1285-z.

[4] Salameh H, Raff E, Erwin A, Seth D, Nischalke HD, Falleti E, et al. PNPLA3 gene polymorphism is associated with predisposition to and severity of alcoholic liver disease. Am J Gastroenterol 2015;110:846-856. doi: 10.1038/ajg.2015.137.

[5] Kienesberger PC, Oberer M, Lass A, Zechner R. Mammalian patatin domain containing proteins: a family with diverse lipolytic activities involved in multiple biological functions. J Lipid Res 2009;50 Suppl:S63-S68. doi: 10.1194/ jlr.R800082-JLR200.

[6] Kershaw EE, Hamm JK, Verhagen LA, Peroni O, Katic M, Flier JS. Adipose triglyceride lipase: function, regulation by insulin, and comparison with adiponutrin. Diabetes 2006;55:148-157. doi: 10.2337/diabetes.55.01.06.db05-0982.

[7] Day CP. From fat to inflammation. Gastroenterology $2006 ; 130: 207-210$. doi: $10.1053 /$ j.gastro.2005.11.017.

[8] Sookoian S, Pirola C]. Meta-analysis of the influence of I148M variant of patatin-like phospholipase domain containing 3 gene (PNPLA3) on the susceptibility and histological severity of nonalcoholic fatty liver disease. Hepatology 2011;53:1883-1894. doi: 10.1002/hep.24283.

[9] Xu R, Tao A, Zhang S, Deng Y, Chen G. Association between patatin-like phospholipase domain containing 3 gene (PNPLA3) polymorphisms and nonalcoholic fatty liver disease: a HuGE review and meta-analysis. Sci Rep 2015; 5:9284. doi: 10.1038/srep09284. 
[10] Zhang $\mathrm{L}$, You $\mathrm{W}$, Zhang $\mathrm{H}$, Peng $\mathrm{R}$, Zhu $\mathrm{O}$, Yao $\mathrm{A}$, et al. PNPLA3 polymorphisms (rs738409) and non-alcoholic fatty liver disease risk and related phenotypes: a meta-analysis. J Gastroenterol Hepatol 2015;30:821-829. doi: 10.1111/jgh.12889.

[11] Stroup DF, Berlin JA, Morton SC, Olkin I, Williamson GD, Rennie D, et al. Metaanalysis of observational studies in epidemiology: a proposal for reporting. Meta-analysis Of Observational Studies in Epidemiology (MOOSE) group. JAMA 2000;283:2008-2012. doi: 10.1001/jama.283.15.2008.

[12] Available at: http://www.ohri.ca/programs/clinical_epidemiology/oxford. asp.

[13] Ungaro R, Bernstein CN, Gearry R, Hviid A, Kolho KL, Kronman MP, et al. Antibiotics associated with increased risk of new-onset Crohn's disease but not ulcerative colitis: a meta-analysis. Am J Gastroenterol 2014;109:17281738. doi: 10.1038/ajg.2014.246.

[14] Minelli C, Thompson JR, Abrams KR, Thakkinstian A, Attia J. How should we use information about HWE in the meta-analyses of genetic association studies? Int J Epidemiol 2008;37:136-146. doi: 10.1093/ije/dym234.

[15] Rodriguez S, Gaunt TR, Day IN. Hardy-Weinberg equilibrium testing of biological ascertainment for Mendelian randomization studies. Am J Epidemiol 2009;169:505-514. doi: 10.1093/aje/kwn359.

[16] DerSimonian R, Laird N. Meta-analysis in clinical trials. Control Clin Trials 1986;7:177-188. doi: 10.1016/0197-2456(86)90046-2.

[17] Higgins JP, Thompson SG, Deeks JJ, Altman DG. Measuring inconsistency in meta-analyses. BMJ 2003;327:557-560. doi: 10.1136/bmj.327.7414.557.

[18] Deeks J], Altman DG, Bradburn MJ. Statistical methods for examining heterogeneity and combining results from several studies in meta-analysis. In: Egger M, Davey Smith G, Altman DG, eds, (ed.). Systematic reviews in health care: meta-analysis in context, 2nd edition. London: BMJ Books, 2005, p.285-312.

[19] Begg CB, Mazumdar M. Operating characteristics of a rank correlation test for publication bias. Biometrics 1994;50:1088-1101. doi: 10.2307/2533446.

[20] Egger M, Davey Smith G, Schneider M, Minder C. Bias in meta-analysis detected by a simple, graphical test. BMJ 1997;315:629-634. doi: 10 . 1136/bmj.315.7109.629.

[21] Duval S, Tweedie R. Trim and fill: A simple funnel-plot-based method of testing and adjusting for publication bias in meta-analysis. Biometrics 2000;56:455-463. doi: 10.1111/j.0006-341X.2000.00455.x.

[22] Available at: http://finzi.psych.upenn.edu/library/metafor/html/trimfill.html.

[23] Hamza S, Petit JM, Masson D, Jooste V, Binquet C, Sgro C, et al. PNPLA3 rs738409 GG homozygote status is associated with increased risk of hepatocellular carcinoma in cirrhotic patients. J Hepatol 2012;56:S281-S282. doi: 10.1016/S0168-8278(12)60725-9.

[24] Way M, McQuillin A, Gurling HMD, Morgan MY. The PNPLA3 I148M mutation significantly increases the risk of developing alcohol-related cirrhosis in alcohol-dependent individuals. J Hepatol 2013;58:S563-S564. doi: 10. 1016/S0168-8278(13)61403-8.

[25] Dutta AK. Genetic factors affecting susceptibility to alcoholic liver disease in an Indian population. Ann Hepatol 2013;12:901-907.

[26] Nguyen-Khac E, Houchi H, Dreher ML, Herpe YE, Naassila M. Is PNPLA3 polymorphism involved in severe acute alcoholic hepatitis. Hepatology 2011;54: 976A.

[27] Bhatt SP, Nigam P, Misra A, Guleria R, Pandey RM, Pasha MA. Genetic variation in the patatin-like phospholipase domain-containing protein-3 (PNPLA-3) gene in Asian Indians with nonalcoholic fatty liver disease. Metab Syndr Relat Disord 2013;11:329-335. doi: 10.1089/met.2012.0064.

[28] Burza MA, Pirazzi C, Maglio C, Sjöholm K, Mancina RM, Svensson PA, et al. PNPLA3 I148M (rs738409) genetic variant is associated with hepatocellular carcinoma in obese individuals. Dig Liver Dis 2012;44:1037-1041. doi: 10. 1016/j.dld.2012.05.006.

[29] Romeo S, Kozlitina J, Xing C, Pertsemlidis A, Cox D, Pennacchio LA, et al. Genetic variation in PNPLA3 confers susceptibility to nonalcoholic fatty liver disease. Nat Genet 2008;40:1461-1465. doi: 10.1038/ng.257.

[30] Santoro N, Kursawe R, D'Adamo E, Dykas DJ, Zhang CK, Bale AE, et al. A common variant in the patatin-like phospholipase 3 gene (PNPLA3) is associated with fatty liver disease in obese children and adolescents. Hepatology 2010;52:1281-1290. doi: 10.1002/hep.23832.

[31] Kantartzis K, Peter A, Machicao F, Machann J, Wagner S, Königsrainer I, et al. Dissociation between fatty liver and insulin resistance in humans carrying a variant of the patatin-like phospholipase 3 gene. Diabetes 2009;58:26162623. doi: $10.2337 / \mathrm{db09}-0279$.

[32] Sookoian S, Castaño GO, Burgueño AL, Gianotti TF, Rosselli MS, Pirola CJ. A nonsynonymous gene variant in the adiponutrin gene is associated with nonalcoholic fatty liver disease severity. J Lipid Res 2009;50:2111-2116. doi: 10.1194/jlr.P900013-JLR200.

[33] Petit JM, Guiu B, Masson D, Duvillard L, Jooste V, Buffier $P$, et al. Specifically PNPLA3-mediated accumulation of liver fat in obese patients with type 2 diabetes. J Clin Endocrinol Metab 2010;95:E430-E436. doi: 10.1210/jc. 2010-0814.

[34] Valenti L, Al-Serri A, Daly AK, Galmozzi E, Rametta R, Dongiovanni P, et al. Homozygosity for the patatin-like phospholipase-3/adiponutrin I148M poly- morphism influences liver fibrosis in patients with nonalcoholic fatty liver disease. Hepatology 2010;51:1209-1217. doi: 10.1002/hep.23622.

[35] Rotman Y, Koh C, Zmuda JM, Kleiner DE, Liang TJ, NASH CRN. The association of genetic variability in patatin-like phospholipase domain-containing protein 3 (PNPLA3) with histological severity of nonalcoholic fatty liver disease. Hepatology 2010;52:894-903. doi: 10.1002/hep.23759.

[36] Goran MI, Walker R, Le KA, Mahurkar S, Vikman S, Davis JN, et al. Effects of PNPLA3 on liver fat and metabolic profile in Hispanic children and adolescents. Diabetes 2010;59:3127-3130. doi: 10.2337/db10-0554.

[37] Speliotes EK, Butler JL, Palmer CD, Voight BF, GIANT Consortium, MIGen Consortium, et al. PNPLA3 variants specifically confer increased risk for histologic nonalcoholic fatty liver disease but not metabolic disease. Hepatology 2010;52:904-912. doi: 10.1002/hep.23768.

[38] Valenti L, Alisi A, Galmozzi E, Bartuli A, Del Menico B, Alterio A, et al. I148M patatin-like phospholipase domain-containing 3 gene variant and severity of pediatric nonalcoholic fatty liver disease. Hepatology 2010;52:1274-1280. doi: $10.1002 /$ hep. 23823 .

[39] Wang CW, Lin HY, Shin SJ, Yu ML, Lin ZY, Dai CY, et al. The PNPLA3 I148M polymorphism is associated with insulin resistance and nonalcoholic fatty liver disease in a normoglycaemic population. Liver Int 2011;31:13261331. doi: 10.1111/j.1478-3231.2011.02526.x.

[40] Hotta K, Yoneda M, Hyogo H, Ochi H, Mizusawa S, Ueno T, et al. Association of the rs738409 polymorphism in PNPLA3 with liver damage and the development of nonalcoholic fatty liver disease. BMC Med Genet 2010;11:172. doi: 10.1186/1471-2350-11-172.

[41] Lin YC, Chang PF, Hu FC, Yang WS, Chang MH, Ni YH. A common variant in the PNPLA3 gene is a risk factor for non-alcoholic fatty liver disease in obese Taiwanese children. J Pediatr 2011;158:740-744. doi: 10.1016/j.jpeds.2010.11.016.

[42] Peng XE, Wu YL, Lin SW, Lu QQ, Hu ZJ, Lin X. Genetic variants in PNPLA3 and risk of non-alcoholic fatty liver disease in a Han Chinese population. PLoS One 2012;7:e50256. doi: 10.1371/journal.pone.0050256.

[43] Kawaguchi T, Sumida Y, Umemura A, Matsuo K, Takahashi M, Takamura T, et al. Genetic polymorphisms of the human PNPLA3 gene are strongly associated with severity of non-alcoholic fatty liver disease in Japanese. PLoS One 2012; 7:e38322. doi: 10.1371/journal.pone.0038322.

[44] Petta S, Grimaudo S, Cammà C, Cabibi D, Di Marco V, Licata G, et al. IL28B and PNPLA3 polymorphisms affect histological liver damage in patients with non-alcoholic fatty liver disease. J Hepatol 2012;56:1356-1362. doi: 10. 1016/j.jhep.2012.01.007.

[45] Zain SM, Mohamed R, Mahadeva S, Cheah PL, Rampal S, Basu RC, et al. A multi-ethnic study of a PNPLA3 gene variant and its association with disease severity in non-alcoholic fatty liver disease. Hum Genet 2012;131:11451152. doi: $10.1007 / \mathrm{s} 00439-012-1141-y$.

[46] Li Y, Xing C, Cohen JC, Hobbs HH. Genetic variant in PNPLA3 is associated with nonalcoholic fatty liver disease in China. Hepatology 2012;55:327-328. doi: 10.1002/hep.24659.

[47] Kitamoto $T$, Kitamoto $A$, Yoneda $M$, Hyogo $H$, Ochi $H$, Nakamura $T$, et al. Genome-wide scan revealed that polymorphisms in the PNPLA3, SAMM50, and PARVB genes are associated with development and progression of nonalcoholic fatty liver disease in Japan. Hum Genet 2013;132:783-792. doi: 10.1007/s00439-013-1294-3.

[48] Islek EE, Sazci A, Ozel MD, Aygun C. Genetic variants in the PNPLA3 gene are associated with nonalcoholic steatohepatitis. Genet Test Mol Biomarkers 2014;18:489-496. doi: 10.1089/gtmb.2014.0019.

[49] Guichelaar MM, Gawrieh S, Olivier M, Viker K, Krishnan A, Sanderson S, et al. Interactions of allelic variance of PNPLA3 with nongenetic factors in predicting nonalcoholic steatohepatitis and nonhepatic complications of severe obesity. Obesity (Silver Spring) 2013;21:1935-1941. doi: 10.1002/oby.20327.

[50] Tai CM, Huang CK, Tu HP, Hwang JC, Chang CY, Yu ML. PNPLA3 genotype increases susceptibility of nonalcoholic steatohepatitis among obese patients with nonalcoholic fatty liver disease. Surg Obes Relat Dis 2015;11:888-894. doi: $10.1016 /$ j. soard.2014.07.016.

[51] Kanth VV, Sasikala M, Rao PN, Steffie Avanthi U, Rao KR, Nageshwar Reddy D. Pooled genetic analysis in ultrasound measured non-alcoholic fatty liver disease in Indian subjects: A pilot study. World J Hepatol 2014;6:435-442. doi: $10.4254 /$ wjh.v6.i6.435

[52] Lin YC, Chang PF, Chang MH, Ni YH. Genetic variants in GCKR and PNPLA3 confer susceptibility to nonalcoholic fatty liver disease in obese individuals. Am J Clin Nutr 2014;99:869-874. doi: 10.3945/ajen.113.079749.

[53] Liu YL, Patman GL, Leathart JB, Piguet AC, Burt AD, Dufour JF, et al. Carriage of the PNPLA3 rs738409 C>G polymorphism confers an increased risk of non-alcoholic fatty liver disease associated hepatocellular carcinoma. J Hepatol 2014;61:75-81. doi: 10.1016/j.jhep.2014.02.030.

[54] Verrijken A, Beckers S, Francque S, Hilden H, Caron S, Zegers D, et al. A gene variant of PNPLA3, but not of APOC3, is associated with histological parameters of NAFLD in an obese population. Obesity (Silver Spring) 2013;21: 2138-2145. doi: 10.1002/oby.20366.

[55] Wagenknecht LE, Palmer ND, Bowden DW, Rotter JI, Norris JM, Ziegler J, et al. Association of PNPLA3 with non-alcoholic fatty liver disease in a 
minority cohort: the Insulin Resistance Atherosclerosis Family Study. Liver Int 2011;31:412-416. doi: 10.1111/j.1478-3231.2010.02444.x.

[56] Akuta N, Kawamura Y, Arase Y, Suzuki F, Sezaki H, Hosaka T, etal. Relationships between genetic variations of PNPLA3, TM6SF2 and histological features of nonalcoholic fatty liver disease in Japan. Gut Liver 2016;10:437-445. doi: $10.5009 /$ gnl15163.

[57] Baulande S, Lasnier F, Lucas M, Pairault J. Adiponutrin, a transmembrane protein corresponding to a novel dietary- and obesity-linked mRNA specifically expressed in the adipose lineage. J Biol Chem 2001;276:33336-33344. doi: 10.1074/jbc.M105193200.

[58] Wilson PA, Gardner SD, Lambie NM, Commans SA, Crowther DJ. Characterization of the human patatin-like phospholipase family. J Lipid Res 2006;47: 1940-1949. doi: 10.1194/jIr.M600185-JLR200.

[59] He S, McPhaul C, Li JZ, Garuti R, Kinch L, Grishin NV, et al. A sequence variation (I148M) in PNPLA3 associated with nonalcoholic fatty liver disease disrupts triglyceride hydrolysis. J Biol Chem 2010;285:6706-6715. doi: 10.1074/jbc. M109.064501.

[60] Chamoun Z, Vacca F, Parton RG, Gruenberg J. PNPLA3/adiponutrin functions in lipid droplet formation. Biol Cell 2013;105:219-233. doi: 10.1111/boc. 201200036.

[61] Paré G, Ridker PM, Rose L, Barbalic M, Dupuis J, Dehghan A, et al. Genomewide association analysis of soluble ICAM-1 concentration reveals novel associations at the NFKBIK, PNPLA3, RELA, and SH2B3 loci. PLoS Genet 2011;7:e1001374. doi: 10.1371/journal.pgen.1001374.

[62] Qu Z, Wu M, Xie T. Expression of ICAM-1 mRNA in HCC using in situ hybridization technique. Zhonghua Bing Li Xue Za Zhi 1997;26:82-84.

[63] Roland CL, Harken AH, Sarr MG, Barnett CC Jr. ICAM-1 expression determines malignant potential of cancer. Surgery 2007;141:705-707. doi: 10 . 1016/j.surg.2007.01.016.

[64] Trépo E, Nahon P, Bontempi G, Valenti L, Falleti E, Nischalke HD, et al. Association between the PNPLA3 ( $r 538409 \mathrm{C}>\mathrm{G}$ ) variant and hepatocellular carcinoma: Evidence from a meta-analysis of individual participant data. Hepatology 2014;59:2170-2177. doi: 10.1002/hep.26767.

[65] Edmondson HA, Peters RL, Frankel HH, Borowsky S. The early stage of liver injury in the alcoholic. Medicine (Baltimore) 1967;46:119-129. doi: 10.1097/ 00005792-196703000-00006.

[66] Naveau S, Giraud V, Borotto E, Aubert A, Capron F, Chaput JC. Excess weight risk factor for alcoholic liver disease. Hepatology 1997;25:108-111. doi: 10 1002/hep.510250120.

[67] Crabb DW. Pathogenesis of alcoholic liver disease: newer mechanisms of injury. Keio J Med 1999;48:184-188. doi: 10.2302/kjm.48.184.

[68] Thornton A, Lee P. Publication bias in meta-analysis: its causes and consequences. J Clin Epidemiol 2000;53:207-216. doi: 10.1016/S0895-4356(99) 00161-4.

[69] Bedossa P. Histological assessment of NAFLD. Dig Dis Sci 2016;61:13481355. doi: $10.1007 / \mathrm{s} 10620-016-4062-0$
[70] Bedossa P, Poitou C, Veyrie N, Bouillot JL, Basdevant A, Paradis V, et al. Histopathological algorithm and scoring system for evaluation of liver lesions in morbidly obese patients. Hepatology 2012;56:1751-1759. doi: 10.1002/hep.25889.

[71] Kleiner DE, Brunt EM, Van Natta M, Behling C, Contos MJ, Cummings OW, et al. Design and validation of a histological scoring system for nonalcoholic fatty liver disease. Hepatology 2005;41:1313-1321. doi: 10.1002/hep. 20701.

[72] Baclig MO, Lozano-Kühne JP, Mapua CA, Gopez-Cervantes J, Natividad FF. Genetic variation I148M in patatin-like phospholipase 3 gene and risk of nonalcoholic fatty liver disease among Filipinos. Int J Clin Exp Med 2014;7: 2129-2136.

[73] Lee SS, Byoun YS, Jeong SH, Woo BH, Jang ES, Kim JW, et al. Role of the PNPLA3 I148M polymorphism in nonalcoholic fatty liver disease and fibrosis in Korea. Dig Dis Sci 2014;59:2967-2974. doi: 10.1007/s10620-014-3279-z.

[74] Park JH, Cho B, Kwon H, Prilutsky D, Yun JM, Choi HC, et al. I148M variant in PNPLA3 reduces central adiposity and metabolic disease risks while increasing nonalcoholic fatty liver disease. Liver Int 2015;35:2537-2546. doi: 10.1111/ liv.12909.

[75] Wei JL, Leung JC, Loong TC, Wong GL, Yeung DK, Chan RS, et al. Prevalence and severity of nonalcoholic fatty liver disease in non-obese patients: a population study using proton-magnetic resonance spectroscopy. Am J Gastroenterol 2015;110:1306-1314; quiz 1315. doi: 10.1038/ajg.2015.235.

[76] Xia MF, Ling Y, Bian H, Lin HD, Yan HM, Chang XX, et al. I148M variant of PNPLA3 increases the susceptibility to non-alcoholic fatty liver disease caused by obesity and metabolic disorders. Aliment Pharmacol Ther 2016; 43:631-642. doi: 10.1111/apt.13521.

[77] Oniki K, Saruwatari J, Izuka T, Kajiwara A, Morita K, Sakata M, et al. Influence of the PNPLA3 rs738409 polymorphism on non-alcoholic fatty liver disease and renal function among normal weight subjects. PLoS One 2015;10: e0132640. doi: 10.1371/journal.pone.0132640.

[78] Nishioji K, Mochizuki N, Kobayashi M, Kamaguchi M, Sumida Y, Nishimura T, et al. The Impact of PNPLA3 rs738409 genetic polymorphism and weight gain $\geq 10 \mathrm{~kg}$ after age 20 on non-alcoholic fatty liver disease in non-obese Japanese individuals. PLoS One 2015;10:e0140427. doi: 10.1371/journal. pone.0140427.

[79] Tai CM, Huang CK, Tu HP, Hwang JC, Chang CY, Yu ML. PNPLA3 genotype increases susceptibility of nonalcoholic steatohepatitis among obese patients with nonalcoholic fatty liver disease. Surg Obes Relat Dis 2015;11:888-894. doi: 10.1016/j.soard.2014.07.016.

[80] Tai CM, Huang CK, Tu HP, Hwang JC, Yeh ML, Huang CF, et al. Interactions of a PPARGC1A Variant and a PNPLA3 variant affect nonalcoholic steatohepatitis in severely obese Taiwanese patients. Medicine (Baltimore) 2016;95:e3120. doi: 10.1097/MD.0000000000003120.

[81] Honda Y, Yoneda M, Kessoku T, Ogawa Y, Tomeno W, Imajo K, et al. The characteristics of non-obese NAFLD: Effect of genetic and environmental factors. Hepatol Res 2016. doi: 10.1111/hepr.12648. 